\title{
EFEKTIVITAS MODEL PEMBELAJARAN KOOPERATIF SCRIPT UNTUK MENINGKATKAN PRESTASI BELAJAR PADA MATA PELAJARAN ILMU PENGETAHUAN SOSIAL
}

\author{
Ilham Rahmawati1 ${ }^{1}$ Cicilia Melinda ${ }^{2}$ \\ 1,2 Program Studi Pendidikan IPS, Universitas Pasir Pengaraian \\ e-mail: Ilhamrahmawati4@gmail.com
}

\begin{abstract}
ABSTRAK
The low student achievement in social studies topics motivates this research. This is because the teacher's learning process still applies the conventional learning model. So academic performance in social studies topics is low. The Cooperative Script model is very appropriate to improve student achievement in learning process, as this model can encourage cooperation and student activity in mastering lessons to achieve maximum academic performance. The purpose of this study was to examine the efficacy of the script-cooperative learning model to improve social studies for SMP N students in Rokan Hulu Regency. This type of study is a two-group pretest posttest design research experiment. Population and sample were second-year students of SMP N 12 Tambusai Utara. Data collection method through written testing. Type of statistical analysis was using t-test. Results showed that the cooperative learning model of script is more effective than conventional learning model to improve student learning outcomes. This study focuses on the script cooperative learning model to improve student achievement in junior high school social studies subjects. The results of this study can be used as reference material for further research using different variables. Such as a cooperative script learning model to increase student learning activity.
\end{abstract}

Keywords: cooperative script model, student achievement, quasi-experiment study

Received: 30 Maret 2021

Accepted: 06 Juni 2021

Published: 28 Juni 2021

\section{PENDAHULUAN}

Pendidikan ilmu sosial memegang peranan penting dalam kehidupan sosial masyarakat, berbangsa serta bernegara. Sebagai makhluk sosial tidak terlepaskan dari kebutuhan interaksi sosial dalam kehidupan sehari-hari. Penting bagi siswa memiliki pengetahuan dalam pendidikan ilmu sosial yang diajarkan di sekolah. Keberhasilan pencapaian pengetahuan di sekolah atau pendidikan formal diukur dengan prestasi belajar. Menurut Sidi (2020) prestasi belajar merupakan hasil yang diperoleh seorang siswa setelah melalui proses belajar. Dalam meningkatkan prestasi belajar, guru sebagai fasilitator harus dapat melakukan perbaikan mutu 
proses pembelajaran di kelas serta memiliki model dan teknik pembelajaran yang tepat sehingga pembelajaran berjalan lebih efektif, menyenangkan, dan dapat mengurangi tingkat kejenuhan siswa selama belajar. Faktanya, sering ditemukan pembelajaran Ilmu Pengetahuan Sosial (IPS) di kelas hanya menggunakan metode konvensional, misalnya ceramah. Hal ini menyebabkan siswa mudah bosan dan jenuh selama di kelas (Norshofiati, Hamid, \& Bakri, 2017). Kejenuhan siswa dalam belajar akhirnya dapat menurunkan minat dan motivasi belajar sehingga prestasi belajarpun akan menurun (Riswanto \& Aryani, 2017).

Pembelajaran IPS hendaknya menjadikan siswa aktif, berpikir kritis dan berinteraksi sesama siswa maupun guru, sehingga prestasi belajar meningkat. Arifin (2009) menyoroti tentang prestasi belajar yang memiliki kaitan dengan aspek pengetahuan pada umumnya, sedangkan yang aspek pembentukan watak peserta didik, salah satunya bersumber dari hasil belajar. Prestasi belajar dipengaruhi oleh faktor eksternal dan internal. Faktor yang berasal dari dalam diri siswa itu sendiri disebut faktor internal, sedangkan yang berasal dari luar diri siswa tersebut disebut faktor eksternal (Slameto, 2008). Contoh dari faktor internal adalah kemampuan memori, kemampuan matematika, kemampuan analisis, kecerdasan intelektual, kebiasaan belajar dan motivasi belajar (Suranto, 2015; Inas, Mulyani, \& Utami, 2016). Faktor eksternal yang mempengaruhi prestasi salah satunya adalah faktor keluarga, faktor sekolah, dan faktor masyarakat (Risfayanti, Sofian, \& Husein, 2015).

Faktor kebiasaan belajar seperti perhatian siswa yang kurang terhadap mata pelajaran IPS di kelas dapat menyebabkan hasil belajar yang rendah. Hal ini ditunjukkan dari hasil belajar siswa mata pelajaran IPS yang belum mencapai Kriteria Ketuntasan Minimal (KKM). Untuk mencapai prestasi belajar siswa pada mata pelajaran IPS diperlukan metode yang efektif sehingga siswa mampu mencapai nilai yang diharapkan. Siswa pada umumnya hanya biasa menerima penjelasan dari guru saja, siswa akan aktif dalam pembelajaran jika diberikan model pembelajaran yang digunakan dapat beraneka ragam atau memiliki banyak variasi. Tugas guru selama proses pembelajaran ialah menerapkan model pembelajaran yang sesuai dengan indikator yang akan dicapai. Hal ini diperlukan agar dapat menciptakan suasana pembelajaran di kelas yang mendukung tercapainya tujuan pembelajaran. Model pembelajaran yang sesuai untuk meningkatkan prestasi belajar siswa salah satunya dengan mengimplementasikan model pembelajaran kooperatif berbasis script.

Model pembelajaran kooperatif script merupakan model pembelajaran yang sesuai untuk melatih keaktifan siswa, siswa berbicara dan saling bertukar informasi sehingga dapat meningkatkan prestasi belajarnya. Siswa yang selalu menerima penjelasan dari guru akan mampu aktif bila diberikan model pembelajaran kooperatif script yang termasuk pembelajaran student centered. Hal ini akan memberikan perubahan dalam pembelajaran IPS di SMP Kabupaten Rokan Hulu yang masih dominan teacher centered. Dimana pembelajaran IPS dominan diberikan dengan metode ceramah. Perubahan pendekatan dari teacher centered ke student

Jurnal Pendidikan IImu Sosial, Vol. 31, No.1, Juni 2021,

p-ISSN: 1412-3835; e-ISSN: 2541-4569 
centered berdasarkan hasil beberapa penelitian dapat meningkatkan motivasi, keaktifan dan prestasi belajar siswa (Emaliana, 2017).

Pembelajaran kooperatif script memberikan kesempatan kepada siswa untuk belajar secara aktif secara berkelompok. Menurut Nur \& Wikandari (2000) menyatakan bahwa model pembelajaran kooperatif script merupakan model pembelajaran yang dilakukan secara berkelompok, bergantian secara lisan untuk merangkum materi yang dipelajari. Model pembelajaran kooperatif script mampu mengembangkan pemahaman siswa pada saat siswa merangkum materi pelajaran (Damayanti, 2018). Selain itu, model kooperatif script juga dapat mendorong lahirnya gagasan baru dalam upaya memecahkan masalah dalam pembelajaran. Hal ini mendorong siswa agar mampu berfikir kritis serta mampu berani menyampaikan hal-hal baru di kelas. Relevan dengan penelitian yang dilakukan Herman, Aminuyati, \& Syahrudin (2018), penggunaan kooperatif script dapat meningkatkan hasil belajar. Sejalan dengan hal tersebut, Giri, Suarni, \& Arini (2018) menjelaskan bahwa model pembelajaran kooperatif script berbantuan media audio visual mampu meningkatkan hasil belajar dan mampu mengatasi hambatan yang terjadi dalam proses pembelajaran. Permasalahan dalam penelitian ini menunjukkan tentang pentingnya meningkatkan prestasi belajar di sekolah. Peneliti telah mengadakan penelitian guna menguji efektivitas model pembelajaran kooperatif script untuk meningkatkan prestasi belajar pada mata pelajaran IPS siswa Sekolah Menegah Pertama (SMP) di Kabupaten Rokan Hulu.

\section{METODE PENELITIAN}

Penelitian ini merupakan penelitian eksperimen semu (quasi-experimental design) (Sugiyono, 2009). The maching only post-test control group design digunakan sebagai desain eksperimen semu. Penelitian ini dilakukan pada Sekolah Menegah Pertama Negeri (SMPN) di Tambusai Utara, Kabupaten Rokan Hulu, Provinsi Riau. Sampel penelitian adalah 31 siswa kelas VIII B SMPN 2 Tambusai Utara yang bertindak sebagai kelas kontrol, sedangkan 31 siswa VIII B SMPN 12 Tambusai Utara sebagai kelas eksperimen. Teknik pengumpulan data menggunakan observasi nonpartisipasi dan tes. Instrumen tes yang digunakan berupa soal IPS berbentuk pilihan ganda. Analisis data menggunakan uji $t$-test dari hasil pretest dan posttest siswa.

\section{HASIL PENELITIAN DAN PEMBAHASAN}

Sebelum eksperimen semu dilakukan pada siswa di SMPN 12 Tambusai Utara, uji validitas dan reliabilitas dilakukan terlebih dahulu pada soal uji coba untuk menguji daya beda dan indeks kesukaran soal. Setelah itu, baru dilaksanakan pretest perlakuan dan kemampuan posttest. Materi pembelajaran dalam penelitian ini adalah tentang Interaksi Ruang di Negara-Negara Asean. Selama pembelajaran di kelas eksperimen, guru memberikan motivasi kepada siswa terlebih dahulu agar 
siswa aktif dan semangat dalam mengikuti pembelajaran yang sedang berlangsung. Selanjutnya, siswa mengetahui tujuan pembelajaran yang akan dicapai.

Guru membagi siswa menjadi berpasangan dalam kelompok terlebih dahulu. Setelah dibagi kelompok siswa akan menerima materi yang diberikan oleh guru untuk didiskusikan secara berpasangan lalu Guru membagikan materi pada tiap siswa untuk dibaca dan dipelajari setelah itu siswa membuat ringkasan mengenai materi yang diberikan oleh guru. Tujuan memberikan materi pada tiap siswa, agar merangsang siswa untuk berfikir dalam menyelesaikan permasalahan sesuai materi. Setelah itu siswa membuat rangkuman atau kesimpulan dari materi yang diberikan oleh guru tersebut.

Pembelajaran dengan menggunakan model kooperatif script dilakukan oleh guru dengan memberikan materi terlebih dahulu. Setelah itu guru menjelaskan dengan menggunakan model kooperatif script sehingga siswa mengetahui langkahlangkah pembelajaran yang akan dilaksanakan sampai proses pembelajaran selesai. Guru dan siswa menetapkan siapa yang pertama berperan sebagai pembicara dan siapa yang berperan sebagai pendengar setelah membuat rangkuman atau kesimpulan dari materi pembelajaran. Setelah itu, siswa harus berdiskusi dengan teman kelompok pasangannya untuk menetapkan siapa yang berperan sebagai pembicara dan berperan sebagai pendengar.

Pembicara membacakan ringkasannnya secara lengkap dengan memasukkan ide pokok dalam ringkasannya, sementara pendengar menyimak atau mengoreksi dan melengkapi ide pokok yang kurang lengkap dan membantu mengingat/menghafal ide pokok dengan menghubungkan materi sebelumnya atau dengan materi faktual lainnya. Hal ini dilakukan setelah ditetapkannya siapa yang berperan sebagai pemateri dan sebagai pendengar. Kegiatan bermain peran tersebut harus adanya pemateri dan pendengar agar siswa lebih maksimal dalam pemahaman konsepnya.

Setelah pemateri pertama memresentasikan materi dan masalah dalam pembelajaran dengan tepat dan jelas. Setelah itu kelompok bertukar peran, yang semula sebagai pembicara ditukar menjadi pendengar begitu juga sebaliknya. Kemudian siswa melakukan seperti kegiatan awal. Hal ini dilakukan agar pada setiap siswa muncul sikap aktif dan kreatif selama pembelajaran sehingga nantinya mampu meningkatkan prestasi belajar siswa terutama pada mata pelajaran IPS. Merumuskan kesimpulan bersama-sama siswa beserta guru setelah siswa bermain peran sebagai penyaji dan pendengar, maka guru mengajak siswa untuk menyimpulkan materi yang dipelajari. Sehingga siswa dapat menghasilkan sebuah script berupa materi pembelajaran sesuai dengan masalah yang diselesaikan dalam pembelajaran. Data hasil pretest dan postest kelas kontrol dan kelas ekperimen dapat dilihat pada Tabel 1.

Jurnal Pendidikan IImu Sosial, Vol. 31, No.1, Juni 2021,

p-ISSN: 1412-3835; e-ISSN: 2541-4569 
Tabel 1.

Rata-rata Hasil Belajar Siswa

\begin{tabular}{ccccc}
\hline \multirow{2}{*}{ Nilai } & \multicolumn{2}{c}{ Eksperimen } & \multicolumn{2}{c}{ Kontrol } \\
\cline { 2 - 5 } & Pre-Test & Post-Test & Pre-Test & Post-Test \\
\hline Terendah & 60 & 75 & 60 & 62 \\
Tertinggi & 63 & 78 & 63 & 66 \\
\hline Rata-Rata & 61,70 & 76,83 & 61,60 & 63,70 \\
\hline
\end{tabular}

Tabel 1 menunjukkan bahwa nilai rata-rata hasil belajar siswa pada kelas eksperimen nilai pretest yaitu 61,70. Hasil ini dapat dikategorikan cukup, dan nilai posttest yaitu 76,83 , yang dapat dikategorikan baik. Sedangkan rata-rata hasil belajar siswa kelas kontrol nilai pretest yaitu 61,60 dikategorikan cukup dan nilai posttest yaitu 63,70 dikategorikan cukup. Hal ini terjadi karena salah satu kelas diberikan perlakuan dengan model kooperatif script sehingga terjadi perbedaan nilai yang dihasilkan.

Pembelajaran dengan menggunakan model kooperatif script pada kelas eksperimen dilakukan dengan memberikan script ke siswa yang diminta untuk dipelajari secara berkelompok pada materi IPS. Langkah berikutnya adalah script tersebut di-review dalam bentuk rangkuman secara berpasangan dalam kelompok. Hasil observasi memperlihatkan pembelajaran menjadi menyenangkan dan pemahaman siswa terhadap konsep menjadi meningkat. Hasil penelitian ini sejalan dengan yang dilakukan oleh Nurshofiati, Hamid, \& Bakri (2017) dan penelitian dari Herman, Aminuyati, \& Syahrudin (2018) bahwa model pembelajaran kooperatif script efektif untuk meningkatkan prestasi belajar siswa, khususnya pada mata pelajaran IPS, jika dibandingkan dengan model pembelajaran konvensional.

Tabel 2.

Hasil Uji t Data Pretest dan Posttest

\begin{tabular}{clcccccc}
\hline Kelas & Hasil & $\mathrm{Db}$ & $\mathrm{X}$ & $\mathrm{SD}^{2}$ & $\mathrm{t}_{\text {hitung }}$ & $\mathrm{t}_{\text {tabel }}(5 \%)$ & Keterangan \\
\hline \multirow{2}{*}{ Eksperimen } & Pre-test & \multirow{2}{*}{30} & 61,70 & 1,02 & \multirow{2}{*}{71,099} & \multirow{2}{*}{1,699} & \multirow{2}{*}{ Signifikan } \\
& Post-test & & 76,83 & 0,95 & & & \\
\multirow{2}{*}{ Kontrol } & Pre-test & \multirow{2}{*}{30} & 61,60 & 0,97 & \multirow{2}{*}{9,090} & \multirow{2}{*}{1,699} & \multirow{2}{*}{ Signifikan } \\
& Post-test & & 63,70 & 1,18 & & \\
\hline
\end{tabular}

Tabel 2 menjelaskan bahwa hasil uji t pada kedua kelas sampel penelitian, dimana kelas eksperimen diberikan perlakuan pembelajaran model kooperatif script dan kelas kontrol menggunakan model pembelajaran secara konvensional yakni dengan model ceramah. Berdasarkan uji hipotesis yang telah dilakukan dengan uji $\mathrm{t}$ diperoleh $\mathrm{t}_{\text {hitung }}=71.099>\mathrm{t}_{\text {tabel }}=1.699$ yang berarti $\mathrm{H}_{0}$ ditolak dan $\mathrm{H}_{\mathrm{a}}$ diterima, dengan kesimpulan signifikan/berpengaruh pada kelas eksperimen. Berdasarkan uji hipotesis yang telah dilakukan dengan uji t diperoleh $t_{\text {hitung }}=9.090$ $>t_{\text {tabel }}=1.699$ yang berarti $\mathrm{H}_{0}$ ditolak dan $\mathrm{H}_{\mathrm{a}}$ diterima, dengan kesimpulan berpengaruh pada kelas kontrol.

Jurnal Pendidikan IImu Sosial, Vol. 31, No.1, Juni 2021, 
Kegiatan yang dilakukan pada kelas eksperimen yaitu memberikan pembelajaran dengan model kooperatif script. Siswa dibagi menjadi 5 kelompok dengan tiap kelompok terdapat 3 pasangan untuk membuat kesimpulan atau rangkuman dari materi yang dipelajarinya sehingga diperoleh rangkuman materi dalam bentuk script dengan sub materi yang berbeda dalam tiap kelompoknya. Kelas kontrol dalam pembelajarannya tanpa menerapkan model pembelajaran kooperatif script, hanya belajar dengan sistem konvensional atau mendengarkan penjelasan yang disampaikan oleh guru. Terlihat dalam tabel 2 pembelajaran dengan menerapkan model kooperatif script dapat meningkatkan prestasi belajar siswa dengan nilai awal pretest sebesar 61,70 meningkat pada posttest menjadi 76,83 . Sedangkan pada kelas kontrol yang menggunakan metode konvensional juga terjadi peningkatan hasil belajar yaitu dari pre test 61,60 menjadi 63,70. Peningkatan hasil belajar pada kelas kontrol tidak signifikan dan lebih rendah dibanding dengan peningkatan pada kelas ekperimen yang menggunakan model kooperatif script.

Sejalan dengan penelitian yang dilakukan oleh Hidayat, Towaf, \& Ruminiati (2017) tentang penerapan model pembelajaran kooperatif script berbantuan mind map untuk meningkatkan keterampilan berpikir kritis dan hasil belajar IPS siswa. Hasil penelitian tersebut menunjukkan bahwa penerapan model pembelajaran kooperatif script berbantuan mind map dalam meningkatkan keterampilan berpikir kritis dan hasil belajar IPS dapat digunakan dan terjadi peningkatan.

Penelitian yang telah dilakukan membuktikan bahwa model kooperatif script dapat meningkatkan prestasi belajar siswa dalam pembelajaran IPS. Sejalan dengan hasil penelitian ini, penelitian terdahulu juga membuktikan bahwa model pembelajaran kooperatif script mempengaruhi keterampilan berpikir kritis dan hasil belajar kognitif siswa (Boleng, 2014). Diperkuat hasil penelitian yang pernah dilakukan oleh Rahayu (2015) peningkatan ketrampilan berpikir kritis siswa diperoleh dengan implementasi model kooperatif script. Dengan hasil penelitian ini dan diperkuat dengan hasil penelitian lainnya maka dapat menjadikan alternatif bagi guru IPS SMP untuk dapat menggunakan metode kooperatif script ini dalam pembelajaran di kelas.

\section{KESIMPULAN}

Hasil penelitian membuktikan bahwa model pembelajaran kooperatif script lebih efektif dibandingkan model pembelajaran konvensional untuk meningkatkan prestasi belajar siswa pada mata pelajaran IPS SMP. Jika penerapan kooperatif script dilakukan dengan langkah-langkah pembelajaran yang tertib, materi pembelajaran yang sesuai, dan motivasi belajar siswa yang baik maka akan dapat meningkatkan hasil belajar siswa. Peneliti merekomendasikan bagi peneliti selanjutnya untuk dapat menggunakan variabel pengukuran yang berbeda, misalnya efektivitas model kooperatif script terhadap kreativitas belajar siswa atau aspek lainnya.

Jurnal Pendidikan IImu Sosial, Vol. 31, No.1, Juni 2021,

p-ISSN: 1412-3835; e-ISSN: 2541-4569 


\section{DAFTAR PUSTAKA}

Arifin, Z. 2009. Evaluasi Pembelajaran. Jakarta: PT Remaja Rosdakarya

Boleng, D. T. 2014. Pengaruh Model Pembelajaran Cooperative Script dan ThinkPair-Share terhadap Keterampilan Berpikir Kritis, Sikap Sosial, dan Hasil Belajar Kognitif Biologi Siswa SMA Multietnis. Jurnal Pendidikan Sains, 2(2), 74-86.

Damayanti, A. 2018. Implementing Cooperative Script Type of Cooperative Learning Model to Improve Students' Activeness in Learning Social Studies. International Journal Pedagogy of Social Studies, 3(1), 129-136.

Emaliana, I. 2017. Teacher-centered or Student-centered Learning Approach to Promote Learning? Jurnal Sosial Humaniora., 10(2), 59-70.

Herman, Aminuyati, \& Syahrudin, H. 2018. Efektivitas Penggunaan Cooperative Script Untuk Meningkatkan Hasil Belajar IPS SMPN 21 Pontianak. Jurnal Pendidikan dan Pembelajaran Khatulistiwa, 7(12), 1-8.

Inas, S., Mulyani, S, \& Utami, B. 2016. Faktor-Faktor Internal yang Berpengaruh Terhadap Prestasi Belajar Siswa Pada Pokok Bahasan Konsep Mol. PAEDAGOGIA: Jurnal Penelitian Pendidikan, 19(1), 79-89.

Hidayat, I., Towaf, S.M., \& Ruminiati. 2017. Penerapan Model Pembelajaran Cooperative Script Berbantuan Mind Map untuk Meningkatkan Keterampilan Berpikir Kritis Dan Hasil Belajar IPS Siswa Kelas V. Pendidikan DasarPascasarjana Universitas Negeri Malang. Jurnal Pendidikan: Teori, Penelitian, dan Pengembangan, 2(4), 562-568.

Giri, K.Y.Y., Suarni, N.K., \& Arini, N.W. 2018. Pengaruh model pembelajaran kooperatif script berbantuan media audio visual terhadap hasil belajar IPS kelas IV. Mimbar PGSD, 6(1), 63-72.

Norshofiati, Hamid, A., \& Bakri, I. 2017. Efektivitas Model Pembelajaran Cooperatif script dikombinasikan dengan model TPS terhadap kemampuan kritis siswa pada materi koloid kelas XI IPA SMA Negeri 12 Banjarmasin. JCAE, Journal of Chemistry And Education, 1(1), 93-103.

Nur, M., \& Wikandari, R. 2000. Pengajaran Berpusat Kepada Siswa dan Pendekatan Konstruktivis dalam Pembelajaran. Universitas Negeri Surabaya. 
Risfayanti, L., Sofian, H., \& Husin, S. 2015. An Analysis on External Factors Influencing Students English Learning Achievements. Jurnal Pendidikan dan Pembelajaran Khatulistiwa, 4(5), 1-10.

Riswanto, A., \& Aryani, S. 2017. Learning motivation and student achievement: description analysis and relationships both. Couns-Edu: The International Journal of Conseling and Education, 2(1), 42-47.

Rahayu, E. S. 2015. Upaya Meningkatkan Keterampilan Berpikir Kritis Siswa dengan Menggunakan Model Pembelajaran Cooperative Svript pada Mata Pelajaran IPS kelas V UIN Syarif Hidayatullah. Repository UIN Jakarta.

Sidi, P. 2020. Discoblog untuk Meningkatkan Keterampilan Kolaborasi dan Prestasi Belajar Ekonomi Bisnis Siswa Kelas X AKL 2 SMKN 1 Sukoharjo. Jurnal Pendidikan Ilmu Sosial, 30(2), 70-82.

Slameto. 2008. Proses Belajar Mengajar. Jakarta: Bumi Aksara.

Sugiyono. 2009. Metode Penelitian Administrasi. Edisi Revisi. Cetakan XVII; Bandung: Alfabeta.

Suranto. 2015. Pengaruh Motivasi, Suasana Lingkungan dan Sarana Prasarana Belajar terhadap Prestasi Belajar Siswa (Studi Kasus Pada SMA Khusus Putri SMA Islam Diponegoro Surakarta). Jurnal Pendidikan Ilmu Sosial, 25(2), 11-19. 